\title{
Microstructures of Laser Deposited 304L Austenitic Stainless Steel
}

\author{
John A. Brooks ${ }^{1}$, Thomas J. Headley ${ }^{2}$ and Charles V. Robino ${ }^{2}$
}

Sandia National Laboratories, Livermore, $\mathrm{CA}^{1} /$ Albuquerque, $\mathrm{NM}^{2}$

\begin{abstract}
Laser deposits fabricated from two different compositions of 304L stainless steel powder were characterized to determine the nature of the solidification and solid state transformations. One of the goals of this work was to determine to what extent novel microstructures consisting of single-phase austenite could be achieved with the thermal conditions of the LENS process. Although ferrite-free deposits were not obtained, structures with very low ferrite content were achieved. It appeared that, with slight changes in alloy composition, this goal could be met via two different solidification and transformation mechanisms.
\end{abstract}

\section{INTRODUCTION}

Near net shape fabrication using the LENS (Laser Engineered Net Shape) process has matured to the point that complex three-dimensional shapes can be reliably processed from a CAD file. However, relatively little work has been conducted to determine to what extent the processing conditions, especially the relatively rapid cooling rates, can be utilized to produce unique or novel microstructures. The austenitic stainless steels are often used for their elevated temperature and corrosion properties, and sometimes for their non-ferromagnetic characteristics. However, in cast or welded materials the properties can be degraded for a number of reasons. These materials often exhibit a two-phase structure of austenite with several percent ferrite $(0-10 \%)$ and in the absence of ferrite, exhibit a considerable amount of microsegregation. At elevated service temperature the ferrite can transform to sigma phase greatly reducing toughness. Ferrite can also affect corrosion behavior and its magnetic characteristics can limit the use of cast material in critical applications. In the absence of ferrite, the high degree of segregation can also degrade corrosion resistance. A large amount of work has been conducted on high-energydensity (HED) welding of the 300 series stainless steels and this work has shown that alloy composition can have a large effect on weld structure and the development of unique microstructures [1-9]. In this study, the ability to develop unique structures, i.e. fully austenitic, in LENS built material of $304 \mathrm{~L}$ alloy was investigated by varying (1) the $\mathrm{Cr}_{\mathrm{eq}} / \mathrm{Ni}_{\mathrm{eq}}$ ratio of the starting powders within the commercial composition range, (2) the solidification velocity via the travel speed of deposition, and (3) the cooling rate via block build (faster) and shell build (slower) deposition geometries.

\section{MATERIALS}

Thermodynamic programs can be used both to predict the alloy phase diagram and to provide input into solidification models for predicting solidification behavior and microstructures $[5,10,11,12]$. Using these concepts, two alloys were designed with different $\mathrm{Cr}_{\mathrm{eq}} / \mathrm{Ni}_{\mathrm{eq}}$ ratios [13] within the commercial 304L composition range. The heat compositions and $\mathrm{Cr}_{\text {eq }} / \mathrm{Ni}_{\text {eq }}$ ratios are given in Table I. The specific $\mathrm{Cr}_{\mathrm{eq}} / \mathrm{Ni}_{\mathrm{eq}}$ ratios were chosen because they were expected to produce single-phase austenite structures via two different solidification/transformation mechanisms when subjected to the high solidification velocity and cooling rate (estimated at $\sim 10,000^{\circ} \mathrm{C} / \mathrm{s}$ ) of pulsed laser welding. Under these conditions, it was expected that heat $\# 2$ would solidify as primary austenite with no residual ferrite, and that heat \#3 would solidify as ferrite but then completely transform to austenite, possibly by a massive transformation. This expected behavior can be understood using a schematic of the Fe-Ni-Cr pseudo binary, figure 1. In a casting or conventional weld, Heat \#2, with $\mathrm{Cr}_{\mathrm{eq}} / \mathrm{Ni}_{\mathrm{eq}}=1.55$ (approximated by $\mathrm{C}_{\mathrm{o}}$ in figure 1), should solidify as primary ferrite with secondary solidification of austenite and contain several percent retained ferrite [14-17]. However, the faster cooling conditions of laser welding were 


\section{DISCLAIMER}

This report was prepared as an account of work sponsored by an agency of the United States Government. Neither the United States Government nor any agency thereof, nor any of their employees, make any warranty, express or implied, or assumes any legal liability or responsibility for the accuracy, completeness, or usefuiness of any information, apparatus, product, or process disclosed, or represents that its use would not infringe privately owned rights. Reference herein to any specific commercial product, process, or service by trade name, trademark, manufacturer, or otherwise does not necessarily constitute or imply its endorsement, recommendation, or favoring by the United States Government or any agency thereof. The views and opinions of authors expressed herein do not necessarily state or reflect those of the United States Government or any agency thereof. 


\section{DISCLAIMER}

Portions of this document may be illegible in electronic image products. Images are produced from the best available original document. 
Table I. Heat compositions and $\mathrm{Cr}_{\mathrm{eq}} \mathrm{Ni}_{\mathrm{eq}}$ ratios

\begin{tabular}{|c|c|c|c|c|c|c|}
\hline Heat\# & $\mathrm{Cr}$ & $\mathrm{Ni}$ & $\mathrm{Mn}$ & $\mathrm{Si}$ & $\mathrm{C}$ & $\mathrm{Cr}_{\mathrm{eq}} / \mathrm{Ni}_{\text {eq }}$ \\
\hline 2 & 19.7 & 11.9 & 1.74 & 0.59 & 0.04 & 1.53 \\
\hline 3 & 20.3 & 10.5 & 1.74 & 0.54 & 0.03 & 1.78 \\
\hline
\end{tabular}

Hammer and Svennson equivalents:

$\mathrm{Cr}_{\mathrm{eq}}=\mathrm{Cr}+1.37 \mathrm{Mo}+1.5 \mathrm{Si}+2 \mathrm{Nb}+3 \mathrm{Ti}$

$\mathrm{Ni}_{\text {eq }}=\mathrm{Ni}+0.31 \mathrm{Mn}+22 \mathrm{C}+14.2 \mathrm{~N}+\mathrm{Cu}$

$\mathrm{Bal} \mathrm{Fe}$

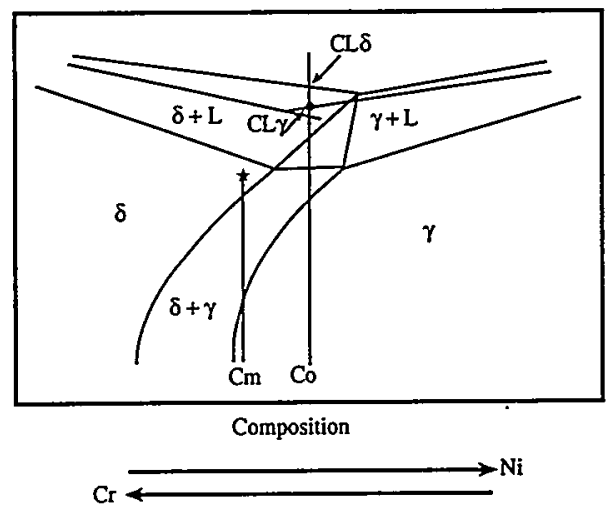

Figure 1. Schematic of Fe-Ni-Cr pseudo binary showing how solidification and transformation behavior can be affected by changing $\mathrm{Cr}_{\mathrm{eq}} / \mathrm{Ni}_{\mathrm{eq}}$ ratio and cooling rate.

expected to produce sufficient undercooling for this heat to solidify as single-phase austenite (the dot where the suppressed $\gamma$-liquidus line intersects $C_{0}$ in figure 1) $[11,12,18]$. Likewise, in a casting or conventional weld, heat \#3, with $\mathrm{Cr}_{\mathrm{eq}} \mathrm{Ni}_{\mathrm{eq}}=1.78$ (approximated by $\mathrm{C}_{\mathrm{m}}$ in figure 1 ), should solidify as primary ferrite with possibly a small amount of secondary solidification of austenite. Then during cooling, all but $\sim 10 \%$ of the ferrite would transform to austenite by a diffusion-controlled transformation [15,17]. However, laser welding was expected to cause this heat to solidify as fully single-phase ferrite. It may then be possible, if the cooling rate through the $\delta+\gamma$ phase field is sufficiently rapid, for the diffusion-controlled transformation to austenite to be suppressed and, upon reaching the single-phase austenite field, for the ferrite to transform massively to austenite.

Since single-phase austenite structures were predicted for these two heat compositions under laser welding conditions, one goal of this work was to investigate whether powders of these compositions could also be fabricated in LENS deposits to yield unique single-phase austenite structures. LENS deposits of both heats were fabricated using three different travel speeds, $8.5,17$, and $34 \mathrm{~mm} / \mathrm{sec}$ to vary the solidification velocity, and two different configurations, shells and blocks, to vary the cooling rates. The shells were made with a singlewidth line deposit to build $6.35 \mathrm{~cm}$ square shells several $\mathrm{cm}$ high. The slice height of each individual layer was approximately $0.254 \mathrm{~mm}$ with a width of $0.5 \mathrm{~mm}$. Blocks $7.6 \mathrm{~cm}$ long and $9.5 \mathrm{~mm}$ wide were built using alternating layers with a $90^{\circ}$ orientation. Slice height of each layer of the several-cm high deposit was approximately $0.254 \mathrm{~mm}$, and the hatch width was approximately $0.4 \mathrm{~mm}$. Cooling rates for the shell builds were measured at $3500^{\circ} \mathrm{C} / \mathrm{s}$. Although cooling rates for the block builds were not measured, they are estimated to be a factor of 1.5-2 greater in the interior of the builds than for the shell builds. After the LENS deposits were fabricated, pulsed YAG laser welds were made on some deposits to verify the predictions of the thermodynamic programs and solidification models that single-phase austenite structures would be produced in these specific compositions under very fast cooling rates. 


\section{RESULTS}

The microstructures of the pulsed YAG laser welds made on the LENS deposits of both heats are shown in figure 2. Figure 2a shows the single-phase austenite microstructure of heat \#2 as predicted for this alloy composition under rapid cooling rates. This microstructure is characteristic of primary austenite solidification. The fine columnar dendritic solidification structure resulting from a small degree of microsegregation, even under the rapid solidification and cooling rates, is clearly visible. Figure $2 \mathrm{~b}$ shows the microstructure of heat $\# 3$ that also appears to be single-phase austenite. It is likely that, as predicted, this weld solidified as singlephase ferrite and transformed completely to austenite during the rapid cooling conditions leaving a fine-grained, single-phase structure. It can be seen that, although both microstructures are single-phase austenite, they differ considerably due to their different solidification and transformation histories.

By contrast, all LENS deposits of both heats contained varying amounts of residual ferrite. The microstructure of a block build LENS deposit of heat \#2 is shown in figure 3 . The lower magnification of figure $3 \mathrm{a}$ shows the two $90^{\circ}$-orientations of the individual LENS deposits. Figure $3 \mathrm{~b}$ at higher magnification shows a region of overlapping passes resulting in two different growth directions. Unlike the laser weld microstructure, the LENS deposit consists of two phases, ferrite and austenite, resulting from primary ferrite solidification and subsequent

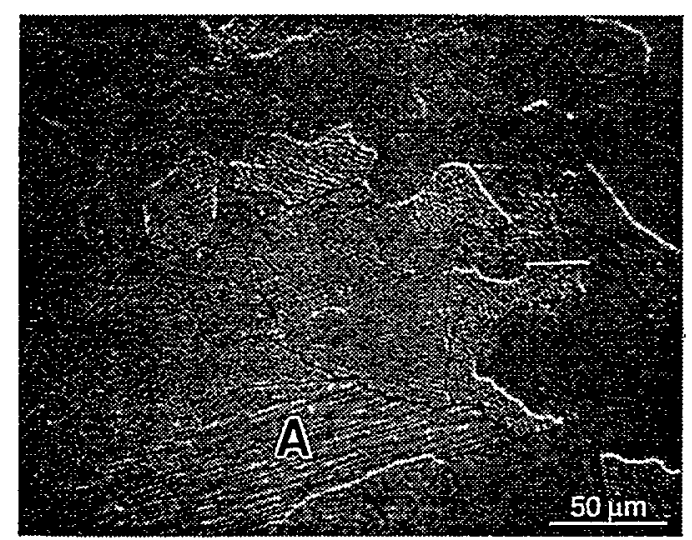

(a)

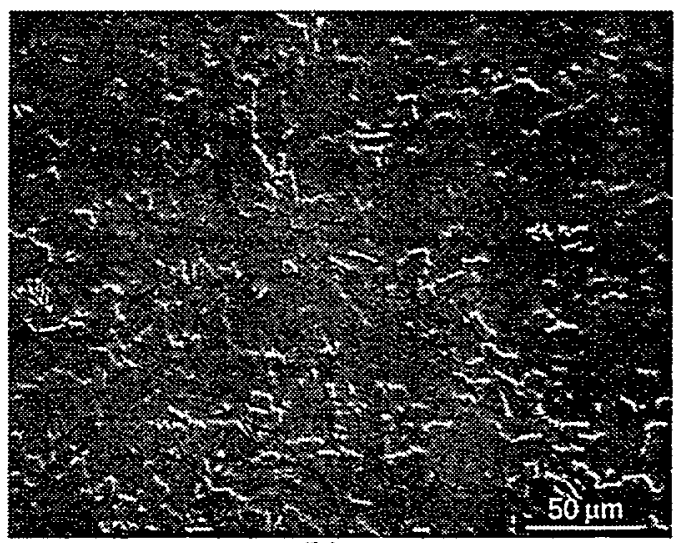

(b)

Figure 2. Optical microstructures of laser welds made on LENS deposits from (a) heat \#2 (note dendrites evident at A), and (b) heat \#3.

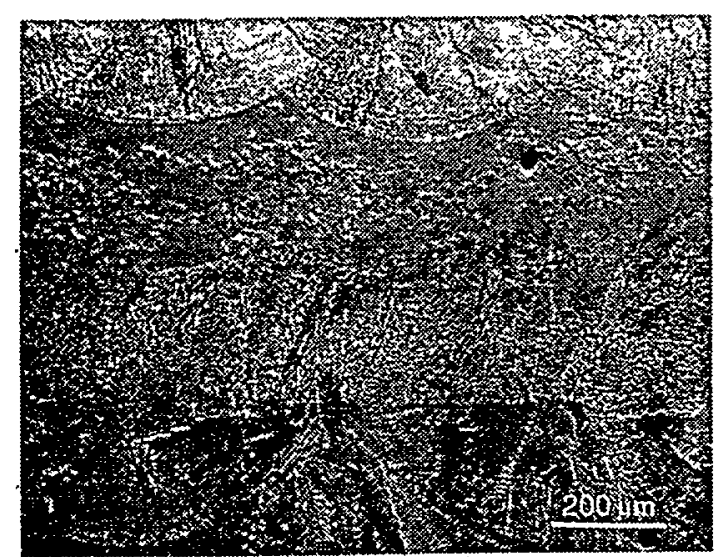

(a)

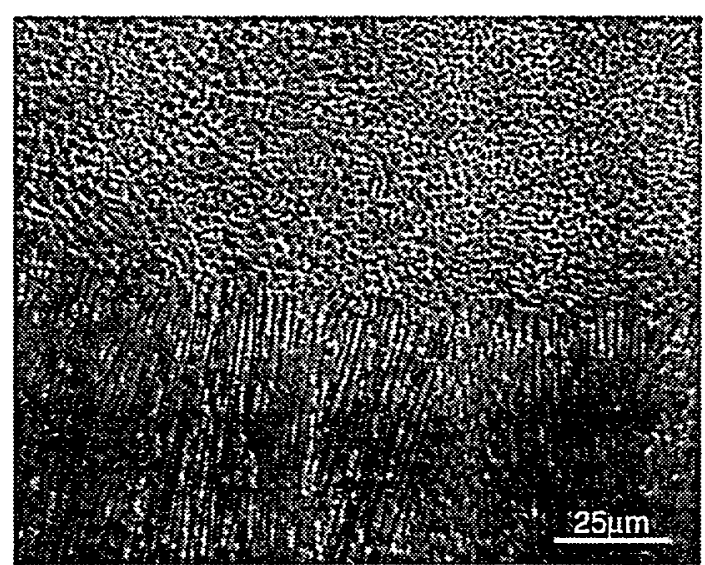

(b)

Figure 3. Optical microstructures of heat $\# 2$ block builds showing (a) different layers and LENS passes. (b) Higher magnification showing region of pass boundary and different solidification growth direction. Dark phase is ferrite along dendrite cores. 
transformation on cooling. TEM studies were conducted on the heat $\# 2$ block to determine the nature of the ferrite and the degree of microsegregation. A low magnification STEM image is shown in figure 4a. The ferrite (dark phase) is distributed along the center of the original dendrite cores. Evidence of microsegregation is also visible due to the differences in polishing rate resulting from the changes in composition. STEM traces were made in two locations: from ferrite in one cell core to ferrite in the adjacent cell core, and also across several solidification cells free of ferrite. The resulting concentration profiles for $\mathrm{Ni}$ and $\mathrm{Cr}$ between two ferrite particles within adjacent dendrite cores are shown in figures $4 \mathrm{~b}$ and $\mathrm{c}$. It can be seen that the cell boundary located between the ferrite is enriched in $\mathrm{Ni}$ and depleted in $\mathrm{Cr}$, while the ferrite is enriched in $\mathrm{Cr}$ and depleted in $\mathrm{Ni}$. This segregation behavior is a result of partitioning both during solidification, where Ni partitions to the liquid, and also during the subsequent solid state transformation of ferrite to austenite where Ni partitions to the austenite and $\mathrm{Cr}$ to the ferrite. Figure 5a shows a region of the same sample in which the cell boundaries are free of ferrite.

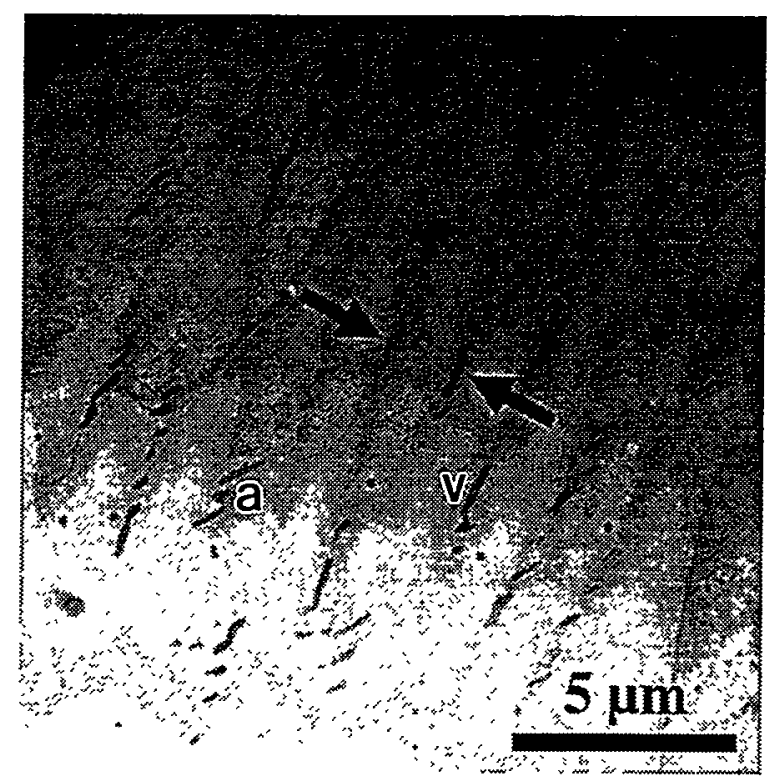

(a)

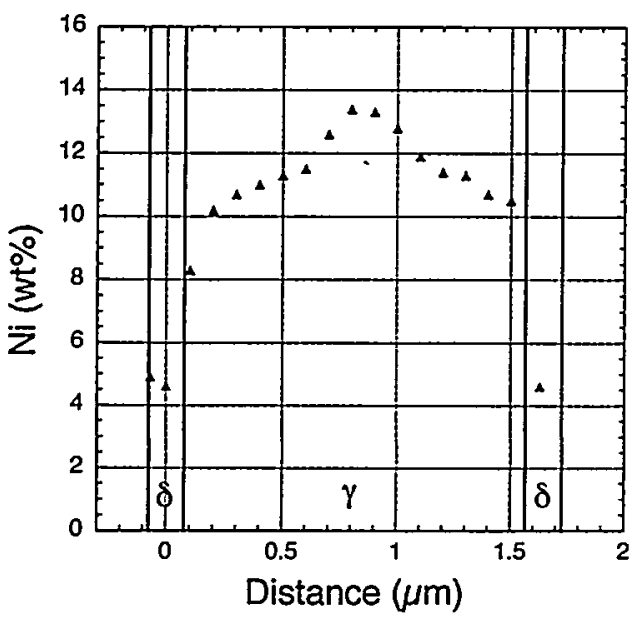

(b)

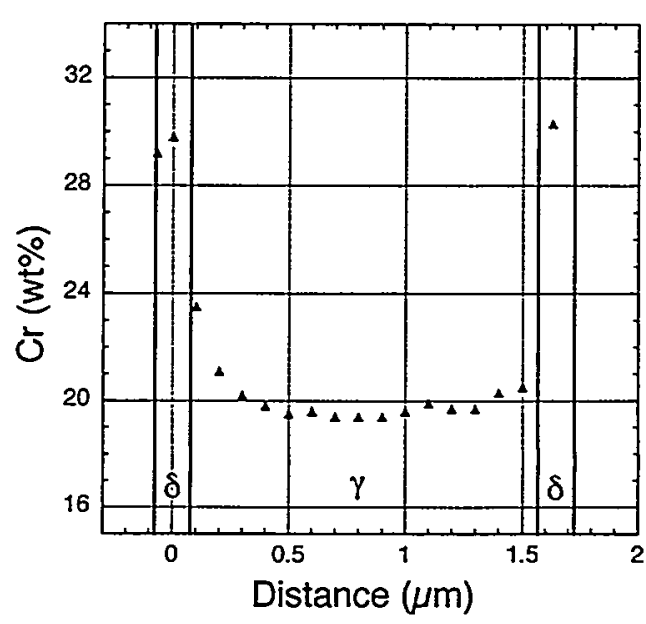

(c)

Figure 4. (a) STEM image from heat \#2 block build showing ferrite along dendrite cores. Note both vermicular (v) and acicular (a) morphologies. (b) and (c) Profiles for $\mathrm{Ni}$ and $\mathrm{Cr}$ between the two ferrite particles (arrows) in (a). 
The profiles in figures $5 \mathrm{~b}$ and $\mathrm{c}$ show the $\mathrm{Ni}$ and $\mathrm{Cr}$ concentrations across the cellular structure where the solidified ferrite transformed completely to austenite. Considerable residual segregation exists as a variation in $\mathrm{Ni}$ of $\sim 3 \mathrm{wt} \%$ and $\mathrm{Cr}$ of $\sim 2 \mathrm{wt} \%$. These profiles are also characteristic of primary ferrite solidification.

It was difficult to identify individual austenite grains in the STEM and TEM bright field images in heat \#2 since much of the grain boundary is coincident within ferrite-austenite boundaries. However, elongated grains $\sim 10 \mu \mathrm{m}$ wide were clearly visible in TEM dark field and have aspect ratios of $\sim 2-4$ to one, with solidification cells oriented parallel to the long direction. TEM results showed there were two general morphologies of the ferrite, both of which can be seen in the STEM image in figure $4 a$. In some grains an elongated vermicular ferrite structure nearly parallel to the cells existed, while in other grains a more acicular ferrite structure existed at an angle to the cell core. All the ferrite within one grain had the same crystallographic orientation. It was found that the acicular structure exhibited a Nishiyama-Wassermann (N-W) orientation relationship $[19,20]$ between the ferrite and austenite. The microstructures of the shell builds of heat \#2 were similar to those of the block builds shown in figures 3 and 4 . Also, there was little observable microstructural difference resulting from change in travel speed (i.e. solidification velocity) for both the shell and block builds.

In contrast to heat \#2, the microstructures of the shell and block builds of heat \#3 were visually quite different, but again changes in travel speed had no apparent microstructural effect. The microstructure of the shell build is shown in figure 6 . In the low magnification micrograph in figure $6 \mathrm{a}$ the individual passes are clearly visible. A region at the interpass boundary is

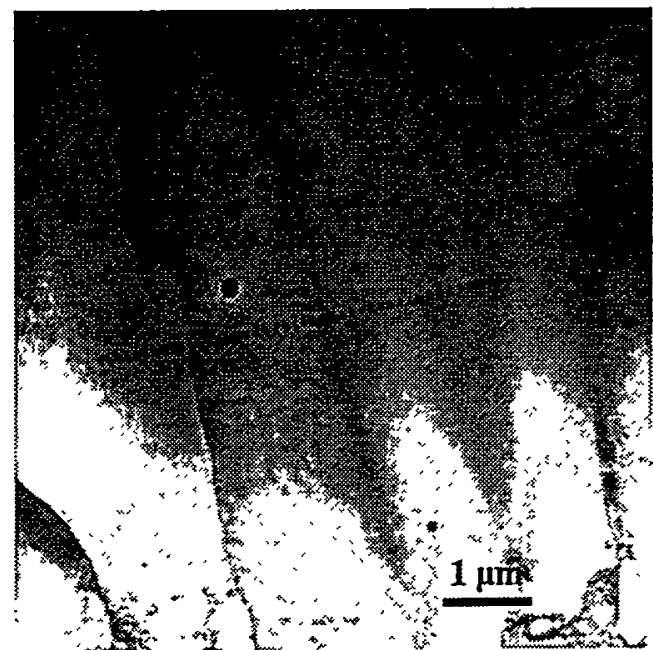

(a)

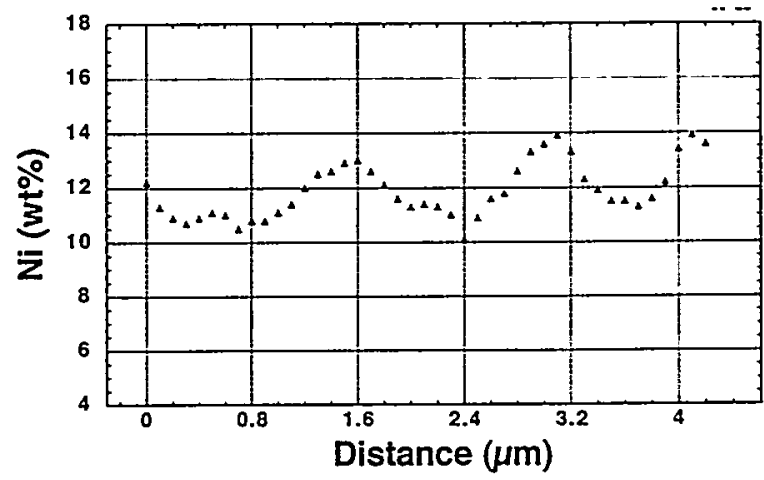

(b)

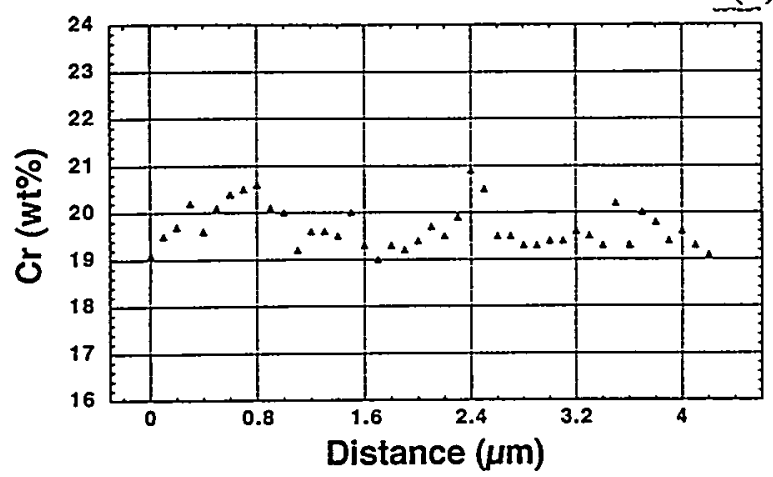

(c)

Figure 5. (a) STEM image of ferrite-free cellular structure in block build of heat \#2 showing location of trace across several cells free of ferrite. (b) and (c) Resulting concentration profiles for $\mathrm{Ni}$ and $\mathrm{Cr}$. 
shown in figure 6b. A fairly complex structure exists with a mixture of grain sizes and internal twins. The dark phase in the microstructure is ferrite, primarily of a lathy morphology [1]. TEM showed that this ferrite was of similar composition to that in heat \#2 shown in figure 4 , i.e. enriched in $\mathrm{Cr}$ and depleted in $\mathrm{Ni}$.

On the other hand, the microstructure of the block build of heat \#3 more closely resembled the laser weld in this material shown in figure $2 \mathrm{~b}$. The optical microstructure of the heat \#3 block build is shown in figure 7. The lower magnification in Figure 7a shows what appears to be a fine-grain, single-phase structure except for a band in the heat-affected-zone (HAZ) at the interpass region apparent near the top of the micrograph. This band contains some second-phase ferrite. A higher magnification image taken near the center of a pass is shown in figure $7 \mathrm{~b}$ where a more duplex structure exists with large grains near the center of the micrograph and regions of smaller grains at the right side. At this magnification some ferrite is observable as small dark spots, especially in the fine-grain regions.

TEM was also conducted on the block build of heat \#3. The solidification cell structure was not as evident as it was in the ferrite-free regions in the build of heat \#2. However, there were a few regions where a faint network of slightly denser-appearing material existed that may correspond to solidification cells. Also, there was much less ferrite present than in the block

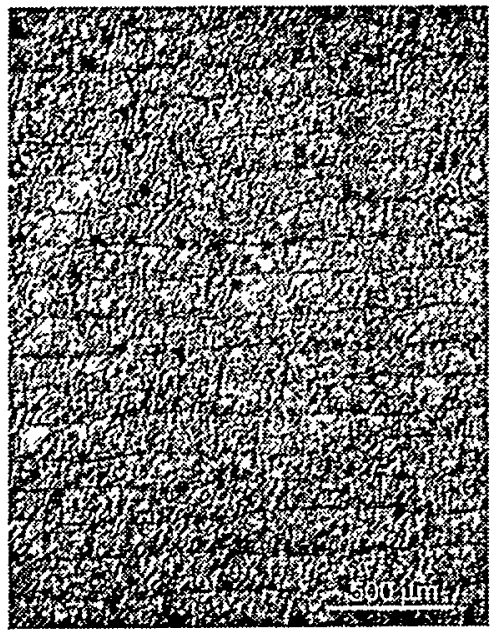

(a)

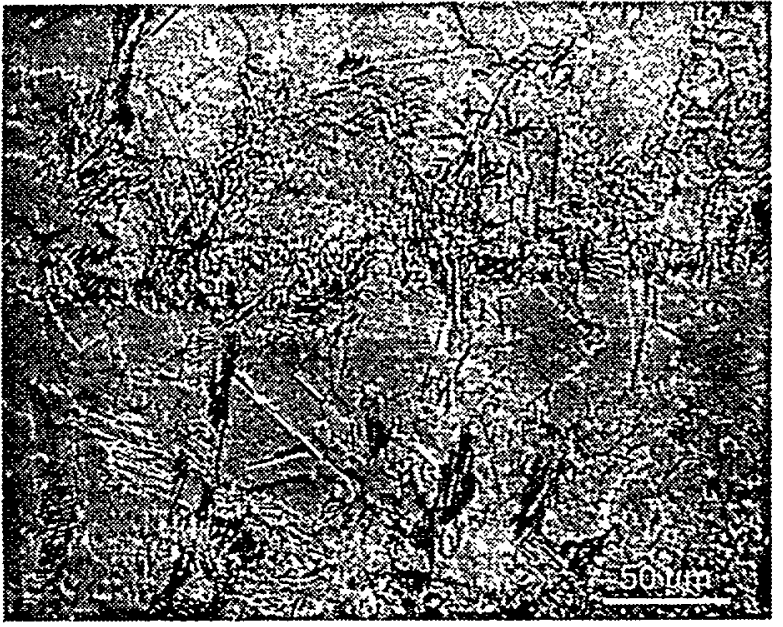

(b)

Figure 6. Optical micrographs of shell build in heat \#3 showing (a) different LENS passes, and (b) higher magnification of interpass region showing ferrite morphology.

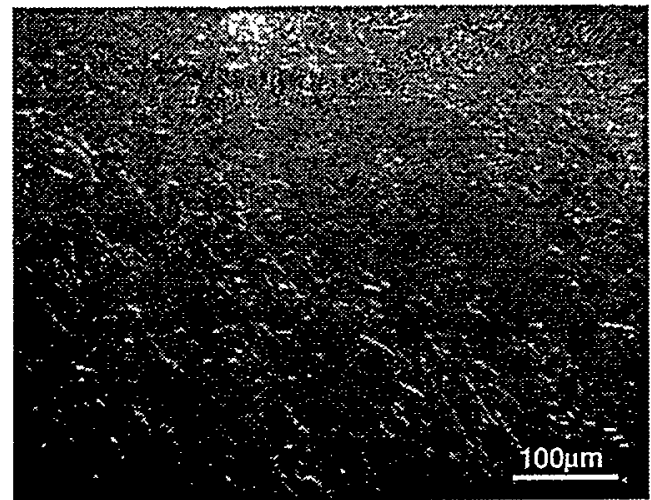

(a)

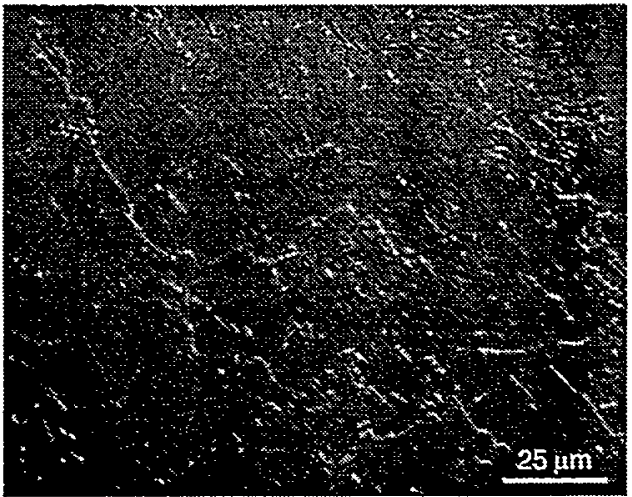

(b)

Figure 7. Optical micrographs of block build of heat \#3. Note in (a) ferrite in HAZ at interpass boundary near top of micrograph and remaining apparent single-phase structure.

(b) Note some residual ferrite more highly concentrated in the finer-grain region. 
build of heat \#2. The austenite grains exhibited a duplex structure, either roughly equiaxed, large grains $10 \mathrm{~s}$ of $\mu \mathrm{m}$ in size and often internally twinned, or groups of smaller grains, $2-4 \mu \mathrm{m}$ in size. This grain structure is consistent with the optical micrograph shown in figure $7 \mathrm{~b}$. The groups of small grains tended to have a common crystallographic direction, i.e. texture, although their boundaries were wide-angle boundaries. These smaller grains tended to be elongated and associated with more ferrite particles than the large equiaxed grains. Ferrite particles tended to be located at grain boundaries in the small-grain regions, although some intragranular ferrite was also observed. The ferrite at the grain boundaries tended to be along the elongated boundaries which were roughly parallel from grain to grain. This morphology may mimic the solidification cell morphology, although this has not been verified. If so, the cells would be $\sim 2 \mu \mathrm{m}$ wide.

The larger equiaxed grains usually contained a few ferrite particles per grain within the thin foil section, and all particles within a given grain were elongated in the same direction suggesting a prior solidification cell structure. A cellular dislocation structure with tangled walls and cell size typically $0.5-1 \mu \mathrm{m}$ was also present within the large grains, figure $8 \mathrm{a}$. There was also a prevalence of long, thin $(\leq 0.1 \mu \mathrm{m}$ wide) ferrite particles on the grain boundaries of the large equiaxed grains, figure $8 \mathrm{~b}$. In the limited regions examined it appeared that as much as 10$20 \%$ of the grain boundary area contained ferrite. This is significantly more than was found on the grain boundaries in heat \#2. Also observed were a few isolated regions of ferrite in long, thin parallel laths, i.e. lathy (or acicular) ferrite, similar to that shown in the optical micrograph of the shell builds in figure 6. Such regions are thought to be associated with the interpass boundaries shown in figure $7 \mathrm{a}$.

STEM EDS analysis was conducted on the heat \#3 block build to determine both the composition of the ferrite and to what extent, if any, microsegregation resulting from solidification or solid state transformations existed. In all cases the ferrite was highly enriched in $\mathrm{Cr}$ and depleted in $\mathrm{Ni}$ compared to the austenite, similar to that shown in figure 4. Results of an analysis for $\mathrm{Ni}$ and $\mathrm{Cr}$ conducted across austenite in the large grain region are shown in figure 9. Figure $9 \mathrm{a}$ shows the trace where the analysis was taken. The profiles in figures $9 \mathrm{~b}$ and $\mathrm{c}$ show that the $\mathrm{Ni}$ and $\mathrm{Cr}$ concentrations are fairly homogeneous with no clear evidence of microsegregation, suggesting a massive transformation from ferrite to austenite may have occurred. The measured value of both elements varies by only $\sim 1 \mathrm{wt} \%$, compared to the $\sim 3 \mathrm{wt} \%$ variation observed in the heat $\# 2$ block build, figures $5 \mathrm{~b}$ and $\mathrm{c}$.

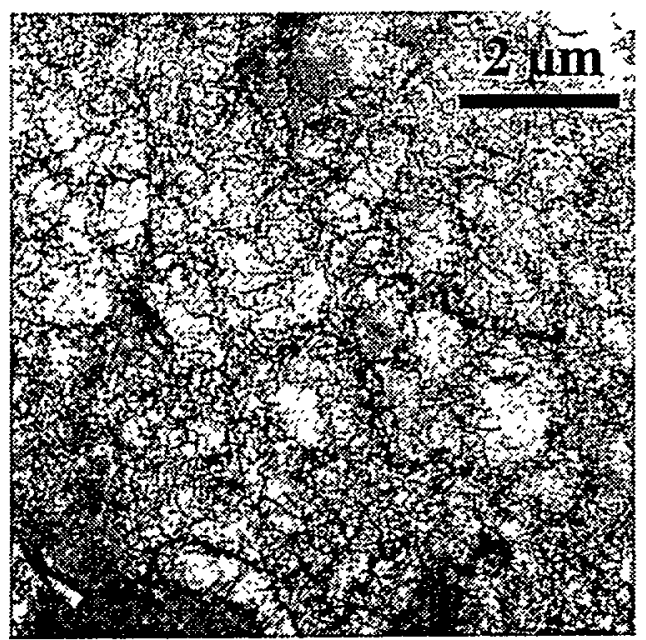

(a)

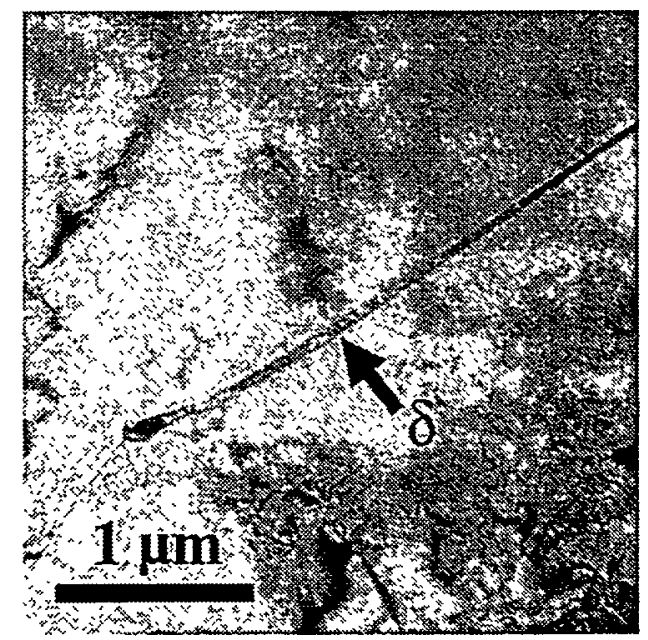

(b)

Figure 8. (a) Dislocation cell structure in large austenite grain in heat \#3 block build. (b) Thin ferrite layer (arrow) on austenite grain boundary. 


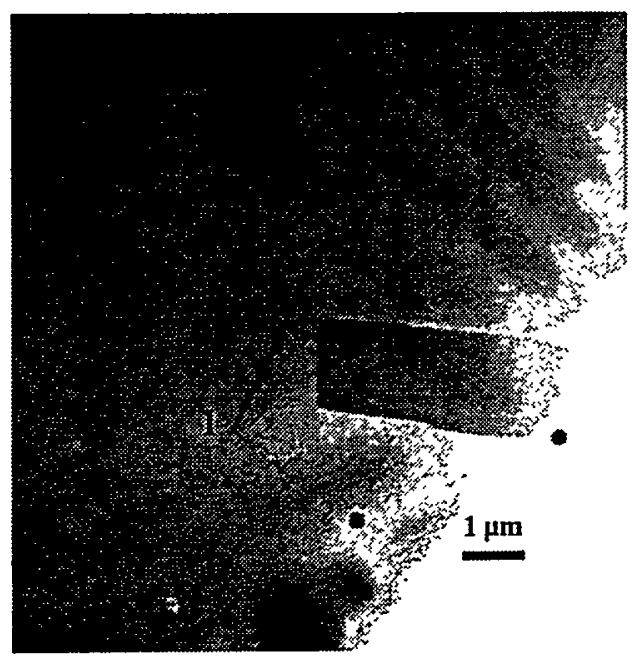

(a)

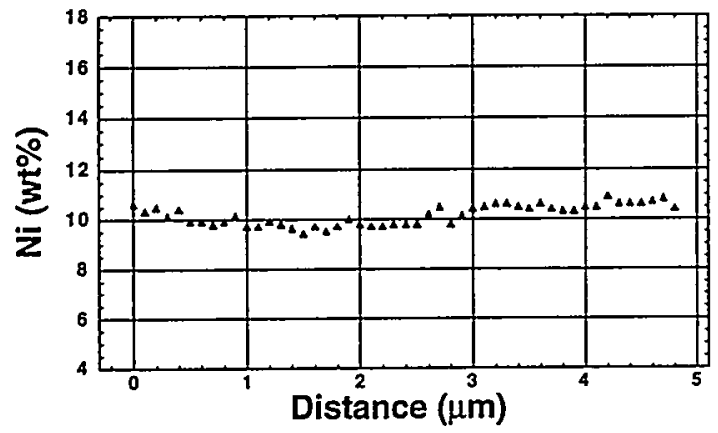

(b)

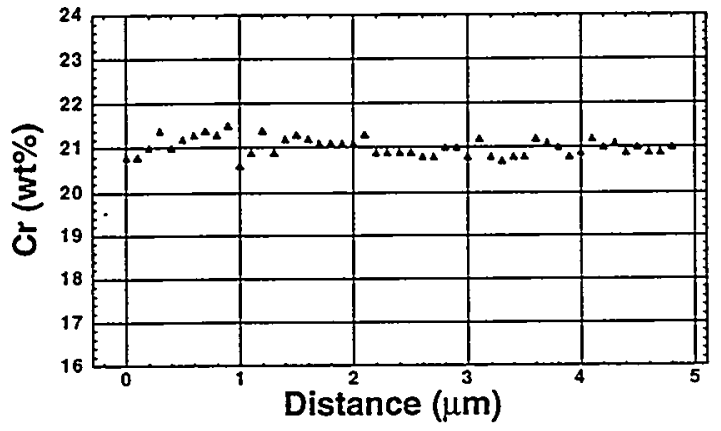

(c)

Figure 9. STEM image in center of large grain of heat \#3 block build showing trace where EDS analysis was made. (b) and (c) Concentration profiles for $\mathrm{Ni}$ and $\mathrm{Cr}$.

\section{DISCUSSION}

There are several mechanisms by which single-phase austenite can be obtained in rapidly solidified 304L deposited material. One is for solidification to occur completely as austenite. Another is for solidification to occur as ferrite, which becomes homogenized during both solidification and cooling in the single-phase ferrite region, and then transforms to austenite during rapid cooling where the transformation occurs massively without any long-range diffusion. If cooling is not sufficiently rapid, partitioning of alloying elements between the two phases occurs during the transformation of ferrite to austenite in the two-phase field, see figure 1. A third possible mechanism exists in lean alloys in which the two-phase field is fairly narrow and the transformation is completed at sufficiently high temperature [21]. In this case the diffusion-controlled transformation of ferrite to austenite may go to completion and leave no retained ferrite.

In heat \#2 it was clear that the solidification conditions were not sufficiently rapid to provide the necessary undercooling for solidification to occur as austenite. It was clear from the ferrite morphology and STEM analysis that solidification occurred as primary ferrite. However, there were some regions of cell boundaries where residual microsegregation of $\mathrm{Cr}$ and $\mathrm{Ni}$ was detected, figure 5, but the cell cores were free of ferrite. It is likely that these are regions in which the transformation of ferrite to austenite went to completion as discussed above. Grains containing the vermicular ferrite likely solidified in a peritectic reaction with secondary austenite growing from the melt [22], whereas grains containing the acicular ferrite solidified completely 
as ferrite. In the latter case, austenite then nucleated in the Ni-enriched cell boundaries with the low-energy $\mathrm{N}-\mathrm{W}$ orientation relationship. Thus heat \#2 did not solidify as primary austenite as predicted for the high solidification rates, but this may possibly be achieved by adjusting the $\mathrm{Cr}_{\mathrm{eq}} \mathrm{Ni}_{\mathrm{eq}}$ ratio to a slightly lower value [17].

With the composition of heat \#3, it appeared that the cooling rates of the pulsed YAG laser welds were sufficiently fast to suppress the diffusion-controlled transformation of ferrite to austenite. Instead, the solidified ferrite likely transformed massively to single-phase austenite. However this was not the case for the LENS deposits. In the shell builds, although there were internally twinned large-grain regions, ferrite was distributed throughout the deposit.

The cooling rates of block builds of alloy \#3 did produce a structure that was very low in ferrite content. The exception was in some HAZ regions at the interpass boundaries, where more ferrite appeared to form by re-heating during subsequent passes into the ferrite phase field, or two-phase ferrite + austenite field, and did not completely re-transform during cooling. In the remainder of the microstructure almost all the ferrite transformed to austenite during cooling. However, unlike some HED welds [1,5], the residual ferrite and austenite were of much different composition, whereas a massive transformation would occur with little change in composition. Also, in many cases thin regions of ferrite were observed along grain boundaries although no evidence of microsegregation could be detected with STEM EDS in the ferrite-free regions. This lack of segregation was also noted in the massively transformed HED welds.

There was a large difference in grain structure of the block builds made from the two heats. The grains in heat \#3 were finer, more equiaxed, facetted, and more internally twinned than those in heat \#2. These grain-structure features, lack of microsegregation, and large regions free of ferrite in the block builds are consistent with a massive transformation [23]. However, the large difference in composition between the residual ferrite and austenite shows that those regions of the microstructure containing residual ferrite transformed by. long-range diffusion. It is also possible that in the ferrite-free regions, the diffusion-controlled transformation went to completion similar to some of the regions observed in heat \#2, figure 4. Thus it is possible that both types of transformation, diffusion-controlled and massive, occurred in heat \#3 which would help explain the reduced amount of ferrite in the block builds. It can be expected that the differences in solidification mode, ferrite/austenite vs. fully ferrite, will also affect (reduce) the final degree of microsegregation.

\section{SUMMARY}

Two alloy variations were designed within the commercial composition range of $304 \mathrm{~L}$ stainless steel to determine to what extent single-phase austenite structures could be fabricated in LENS deposits. Pulsed YAG laser welds on LENS deposits of the two heats did produce singlephase austenite structures, one a direct product of solidification and the other a product of massive transformation of ferrite to austenite. It was found that the LENS fabricated heat of lower $\mathrm{Cr}_{\mathrm{eq}} / \mathrm{Ni}_{\mathrm{eq}}$ ratio, unlike the laser weld, solidified as primary ferrite, likely with some grains solidifying completely as ferrite and others with some secondary solidification of austenite. This was concluded from differences in retained ferrite morphology. However, with a slightly lower $\mathrm{Cr}_{\mathrm{eq}} / \mathrm{Ni}_{\mathrm{eq}}$ ratio, a single-phase austenite structure may be achieved directly as the solidification product. In this case a certain degree of microsegregation would exist.

LENS fabricated heat \#2 with the higher $\mathrm{Cr}_{\mathrm{eq}} / \mathrm{Ni}_{\mathrm{eq}}$ ratio solidified completely as primary ferrite. However, unlike the laser weld, not all the ferrite transformed to austenite upon cooling. The amount of ferrite retained was much less in the more rapidly cooled block builds than in the slower cooled shell builds. It was unclear if some of the structure transformed massively, although large differences between ferrite and austenite compositions showed that some, if not all the structure transformed by a long-range diffusion transformation. It is possible that, with slight modifications in composition, the LENS cooling rates of the block builds may be sufficiently rapid to produce a massively transformed, homogeneous single-phase austenite structure. 


\section{ACKNOWLEDGMENTS}

M. S. Oliver fabricated the LENS deposit specimens. A. D. Gardea performed the metallographic preparation. This work was performed at Sandia National Laboratories, a Lockheed Martin Company, for the U.S. Department of Energy under contract number DE-AC04-94AL85000.

\section{REFERENCES}

1. J. A. Brooks and A. W. Thompson, International Materials Reviews 36 (1), 16 (1991).

2. S. A. David and J. M. Vitek, in Lasers in Metallurgy, edited by K. Mukherjee and J. Mazumder (TMS-AIME, Warrendale, PA, 1981), p. 247.

3. J. M. Vitek, A. Dasgupta, and S. A. David, Metall. Trans. A 14A, 1833 (1983).

4. S. Katayama and A. Matsunawa, in Proc. ICALEO, San Francisco, pp.19-25 (1985).

5. J. A. Brooks, M. I. Baskes and F. A. Greulich, Metall. Trans. A 22A, 915 (1991).

6. J. W. Elmer, S. M. Allen and T. W. Eagar, Metall. Trans. A 20A, 2117 (1989).

7. S. A. David, J. M. Vitek and T. L. Hubble, Weld. J. 66 (10), 289-s (1987).

8. Y. Nakao, K. Nishimoto, and W. Zhang, Trans. JWJ I19, 101 (1988).

9. H. Inoue, T. Koseki, S. Ohkita, ISIJ 1977, 1248.

10. W. Kurz and D. J. Fisher, Fundamentals of Solidification, (Trans Tech Publications Ltd., Switzerland, 1989).

11. S. Fukumoto and W. Kurz, ISIJ International 37 (7), 677 (1997).

12. J. W. Elmer, in The Metals Science of Joining, edited by M. J. Cieslak, Perepezko, Kang and Glicksman, (TMS, Warrendale, PA, 1992) pp.123-133.

13. O. Hammer and U. Svensson, in Solidification and Casting of Metals (The Metals Society, London, 1979), p. 401.

14. T. Takalo, N. Suutula and T. Moisio, Metall. Trans. A 10 (4), 1173 (1979).

15. N. Suutula, Effect of solidification conditions on the solidification mode in austenitic stainless steels, Acta Universitatis Ouluensis, Series C Technica 23, (University of Oulu, Oulu, Finland 1982).

16. N. Suutula, T. Takalo and T. Moisio, Metall. Trans. A 10 (4), 512 (1979).

17. C. J. Long and W. T. DeLong, Weld. J. 52, 281-s (1973).

18. B. Laursen, F. Olsen, J. Yardy and T. Funder-Kristensen, in International Conference on Welding and Joining Science and Technology, Madrid, Spain, (ASM, 1997) pp. 571-580.

19. S. Nishiyama, Sci. Rept., Tokyo Univ. 23, 369 (1993).

20. G. Wasserman, Ach. Eisenhuttenwesen 16, 647 (1933).

21. J. W. Pugh and J. D. Nisbet, Trans. TMS-AIME 188, 268 (1950).

22. J. A. Brooks, N. Yang and J. Krafcik, in Recent Trends In Welding Science and Technology, edited by S. A. David and J. M. Vitek, (ASM International, 1992).

23. D. A. Porter and K. E. Easterling, in Phase Transformations in Metals and Alloys, (Chapman and Hall, 1992), pp.349-358. 